\title{
Pregnancy and Oral Pathology
}

\author{
Nafiou Idi ${ }^{*}$, Mahamane Rhissa Moussa ${ }^{2}$, Souleymane Aichatou Anahi ${ }^{1}$, Kaka Yakoura Abba ${ }^{3}$ \\ ${ }^{1}$ Faculté des Sciences de la Santé, Niamey, Niger \\ ${ }^{2}$ Department de Odontostomatology, Niamey, Niger \\ ${ }^{3}$ Departement of Ophtalmogie, Hospital National de Niamey, Niamey, Niger \\ Email: ^idinafi@yahoo.fr, mahamnerhissa@yahoo.fr
}

How to cite this paper: Idi, N., Moussa, M.R., Anahi, S.A. and Abba, K.Y. (2019) Pregnancy and Oral Pathology. Open Journal of Obstetrics and Gynecology, 9, 1456-1463. https://doi.org/10.4236/ojog.2019.911141

Received: August 29, 2019

Accepted: November 4, 2019

Published: November 7, 2019

Copyright $\odot 2019$ by author(s) and Scientific Research Publishing Inc. This work is licensed under the Creative Commons Attribution International License (CC BY 4.0).

http://creativecommons.org/licenses/by/4.0/

Open Access

\begin{abstract}
Introduction: Dental pathologies during pregnancy can compromise the prognosis of pregnancy and that of the mother. We report a first-study of cases of association of pregnancy and oral pathology supported in the Department of Odonto-stomatology of the National Hospital of Niamey. Objective: To report epidemiology, treatment and prognosis of dental origin cervicofacial cellulitis associated with pregnancy. Patients and Methods: This is a retrospective and prospective study over 5 years from August 1st, 2013 to July 31, 2018 involving 21 pregnant women in the Odonto-stomatology Department of the National Hospital of Niamey (HNN). Results: During the study period, 585 patients were consulted in the Odonto-stomatology Department for cervicofacial tooth cellulitis of dental origin, 21 of them were pregnant women (3.39\%). The average age of the pregnant patients was 29.57 years old, extrems 25 - 29 years old. The average delay before consultation was 28.76 days. Majority patients were rural inhabitants The pathology happened in the third trimester of pregnancy $(52.39 \%)$, second trimester $(33.33 \%)$, in first (14.29\%). This pathology was observed among disadvantaged socioeconomic class as housewives (85.71\%) and uneducated women $(61.90 \%)$. The lake of oral hygien was the main cause of cellulitis. We noted a history of periodontal disease (52.38\%), fever upper $38^{\circ} \mathrm{C}(61.90 \%)$, trismus $(85.71 \%$,) dysphonia (42.86\%), odynophagia (23.81\%), dysphagia (42.86\%), dyspnea $(33.33 \%)$, and cervicofacial swelling (100\%.) The treatment was medico-surgical. The prognosis depended on the precocious treatment with $76.19 \%$ cured. But unfortunately 4 cases died (19.05\%), still for birth $(52.38 \%)$ and 9.52\% abortion. Conclusion: Association dental origin cervicofacial cellulitis with pregnancy is dangerous with bad prognosis for the pregnancy and the mothers in Niger.
\end{abstract}

\section{Keywords}

Cervico-Facial Cellulitis, Pregnancy, Epidemiology, Treatement, Prognosis 


\section{Introduction}

Pregnancy is a special condition for any woman, a physiological state characterized by hormonal, bacteriological and immunological changes throughout the body and especially in the oral cavity [1]. This dental upheaval observed during pregnancy, makes the woman more subject to dental and periodontal affections [2], origin of the cell-adiposis spaces infection involving face and neck, known as cervicofacial cellulitis. Thus pregnancy has been identified as a susceptibility factor to the occurrence and aggravation of cervicofacial cellulitis of dental origin [3]. Oral pathologies can have a significant impact on the course of pregnancy [1]. Cervico-facial cellulitis during pregnancy is important because of the pain they cause, the speed which they can appear and develop, and especially the maternal-fetal complications that they engender, sometimes even fatal (sepsis and maternal-fetal mortality, premature delivery and abortion) [3] and they are part of the dental emergencies to which the odontologist has to face in his daily practice [4]. The absence of an anatomical barrier allows the spread of infection quickly, from the base of the skull to the diaphragm. The infection develops through the bone and periosteum to reach the peri-maxillary cell tissue. It manifests itself in different aspects, both clinical and topographical. These infections happen most often after pulpal necrosis but can sometimes have a different origin, important to determine, during this, various microbial agents very virulent and most often in association will be responsible for a large and very extensive tissue destruction.

It is for this reason that in presence of cellulitis during pregnancy; an effective treatment should be set up early in order to eradicate the infection as soon as possible, while taking into account the teratogenic risk of certain. Drugs in the fetus or embryo and their side effects observed in pregnant women with certain physiological changes such as digestive and renal, were involved in the absorption and metabolism of drugs. This treatment is also intended to prevent the spread of infection and to avoid the risk that it may involve maternal-fetal prognosis. In our context, the frequency of cervicofacial cellulitis during pregnancy is increasing. Patients are seen late and with an urgent need for management for various reasons as self-medication, poor oral hygiene and some socio-economic beliefs popular idea to avoid visit dentist during pregnancy [5] [6]. Cervico-facial cellulitis during pregnancy is one of the major concerns for practitioners of the oro-maxillofacial-facial field and gynecologists in developing countries such as Niger. Their evolution and their vital prognosis were both maternal and fetal or embryonic, especially. Socio-economic difficulties encountered in most of our patients limit the carrying out of certain examinations such as bacteriological examination with antibiogram and also the therapeutic urgency, which leads most often to the initiation of a probabilistic antibiotic therapy, used first intention based on the sole bacteriological presumption [5].

The interest of the choice of our subject, relates to the frequency of higher and higher cellulite during pregnancy in the odontological consultations among the 
poor and the gravity that could take their evolution.

The objective of this work was to study the prognosis of cellulitis during pregnancy.

\section{Patients and Method}

It is a mixed prospective ( 6 cases) and retrospective ( 15 cases) study from $\mathrm{Au}$ gust 1st, 2013 to July 30th, 2018 in the Odonto-stomatology Department of the National Hospital of Niamey (HNN). Were Included 21 pregnant women treated for dental cellulitis, were not included pregnant patients with other oral or facial pathology. For the retrospective cases, we analyzed the archived files and some informations were added through the contact of the former patients. For prospective cases, all informations were recorded in the pre-established survey tested sheets. The parameters were year old age, time between onset of symptoms and consultation, history of pregnancy as abortion, delivery, trimester of pregnancy, living area, profession, level of education, history of sexually transmitted infection, chronic pathology, outcome of pre-treatment assessment (hematologic, serology HIV, serology hepatitis B, glycemia, We did not use antibiogram test (because the patients could not pay this laboratory exam and the urgency imposing an aero-anaerobic broad spectrum antibiotic), treatment and maternal prognosis. The limit of the study was post-discharge follow-up.

All ethical rules respected. We had no conflict of interest.

\section{Results}

\subsection{Epidemiological Characteristics}

The service received 585 cases of cervicofacial cellulitis of dental origin in five years, in which 21 pregnant women (prevalence of 3.39\% of cases) (Figures 1-3).

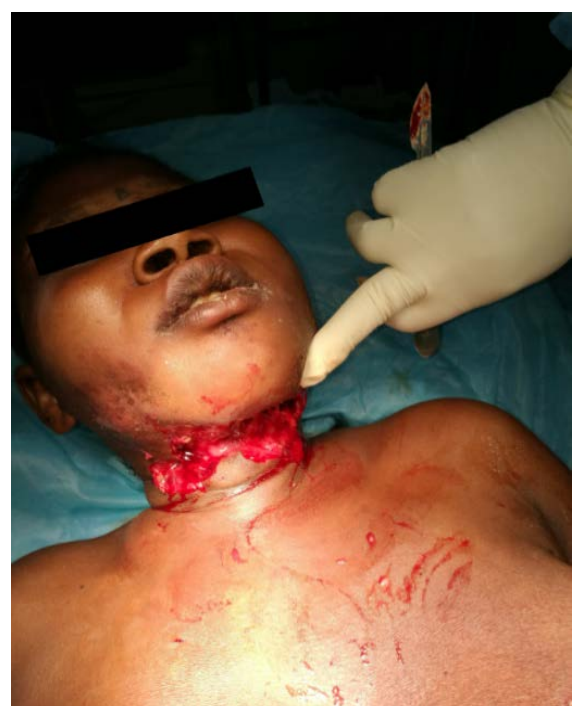

Figure 1. Incision of diffuse cellulitis in a pregnant patient (picture of the HNN stomatology department). 


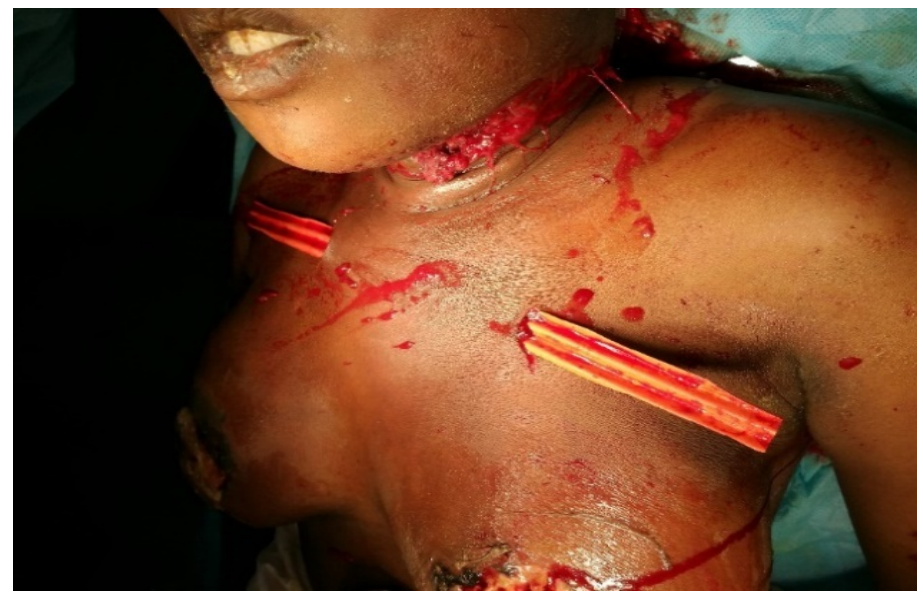

Figure 2. Drainage of a drain in the same patient.

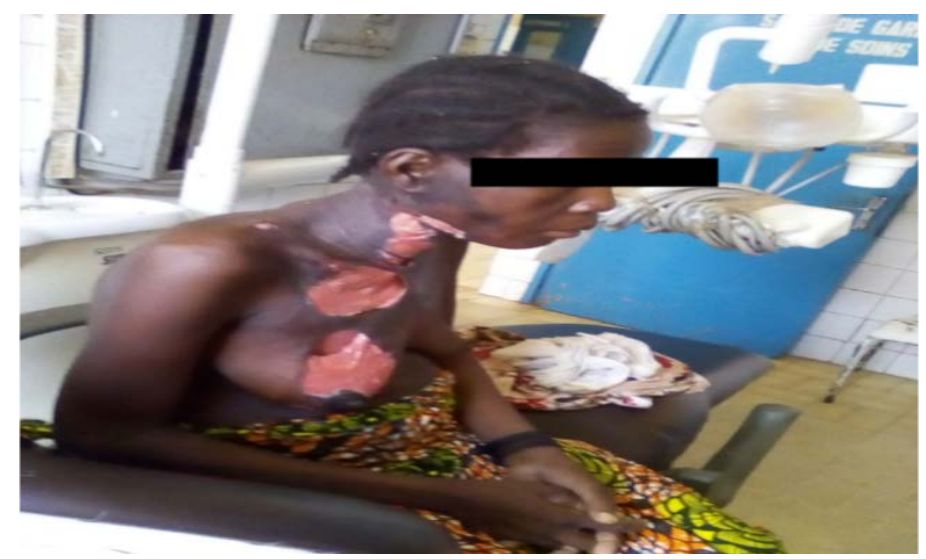

Figure 3. Genital bleeding cellulitis in the mediastinal region with fistula in a recent childbirth (picture of the HNN Stomatology Department).

Delay before consultation was 5 to more 40 days extrems 5 and 59 days (Table 1). The average age of the pregnant women was 29.57 years old, extrems 25 and 29 years old. Patients were uneducated 61.90\%), 1 case had diabetes, $14.29 \%$ hypertensive condition or sickle cell disease (14.29\%); all patients had chronic anemia (hemoglobin level $7-9 \mathrm{~g} / \mathrm{dl}$, and $57.14 \%$ urinary infection, 11 cases of periodontal disease $(52.38 \%)$, HIV1/2 and B hepatitis serology were negative. The main risk factors for this pathology were tooth decay, defective oral hygiene and the addiction of anti-inflammatory drugs without a prescription $(85.71 \%)$ or traditional treatment with decoctions (66.67\%) for dental pain.

Cellulitis was observed in the third pregnancy trimester for 11 patients (52.38\%), 7 in the second trimester (33.33\%) and 3 in the first (14.29\%). The mean time before consultation was 28.76 days, extrems 5 and 59 days (Table 1), Clinical signs were cervical and/or facial swelling with (90.48\%) trismus (85\%), $71 \%$ fever up $38^{\circ} \mathrm{C}(61.90 \%)$, dysphonia as well as dysphagia in 9 patients $(42.86 \%)$, dyspnea (33.33\%) and odynophagia (23.81\%), Cellulitis was mandibular in $85.72 \%$, with predominance on the right side (71.44\%), diffuse clinical 
Table 1. Evolution of pathology before consultation.

\begin{tabular}{ccc}
\hline Delay (days) before consultation & Frequency & $\%$ \\
\hline$<10$ & 3 & 14.29 \\
{$[10-20]$} & 3 & 14.29 \\
{$[20-30]$} & 4 & 19.05 \\
{$[30-40]$} & 5 & 23.80 \\
$>40$ & 6 & 28.57 \\
Total & 21 & 100 \\
\hline
\end{tabular}

forms accounted for $76.20 \%$ in stages 3 and 4 of the general state according to WHO.

\subsection{Treatment}

We used essentially systematic intravenous broad-spectrum antibiotic therapy (amoxicillin/clavulanic acid and metronidazole) and analgesic with mouthwashes antiseptic. Surgical treatment under locoregional anesthesia consisted of drainage incision (85.71\%) and dental avulsion (76.71\%).

\subsection{Prognosis}

The average duration of hospitalization was $21.66 \%$ days with extrems of 4 and 42 days. The cure rate was $76.19 \%, 4(19.05 \%)$ cases of maternal death. 9.5\% abortion, $42.85 \%$ stillbirths were observed (Table 2), 4 pregnancies were progressive at the time of the study.

\section{Discussion}

The majority (18/2l) of our patients came from rural area where no specialist health provider as midwife, dentist access. Patients household were uneducated $(13 / 21)$. This could explain their neglect of oral hygiene and dental care growing to advanced buccal infection. They came to hospital after failing traditional treatment or auto-medication. Some studies have also shown the prevalence of this pathology in the informal sector in with a rate of $52.72 \%$ [4] or $42.8 \%$ and Adja Bintou S. Dakar, housewives with a rate of $61.90 \%$. Thus, it is noted that the pathologies are more frequent affections in the subjects having a low socio-economic level.

The prevalence of cervicofacial cellulitis during pregnancy in this study was $3.39 \%$. This rate is very low compared to $20 \%$ for Badiane [4], Keita (9.7\%) [5]. The age old group 25 - 29 years was the most represented (33.33\%), average age 29.57 years old, Aboulouida L reports 27.5 years old average age [1], 28 years for Nzolo [6]. More than half of cases occurred in the third trimester, 30\% for Keita [5]. We observed $2 / 3$ of the patients were uneducated. The cellulitis would be due to a defective oral hygiene in housewives (18/21). Many studies note the prevalence of this pathology in this group, $52.72 \%$ [4] and $42.8 \%$ [7]. 
Table 2. Pregnancy prognosis.

\begin{tabular}{ccc}
\hline Prognosis & Frequency & $\%$ \\
\hline Abortion [7 - 14 j] before hospitalisation & 2 & 9.525 \\
Evolutive pregnancy & 7 & 33.33 \\
Premature still for birth & 7 & 33.33 \\
Full term home delivery [7 - 14 j] & 3 & 14.29 \\
Full term still for birth & 2 & 9.525 \\
Total & 21 & 100 \\
\hline
\end{tabular}

Cellulitis would be more common among lower socio-economic status people. The pathology developed before the consultation in an average time of about one month (extrems 5 and 59 days), 20 days for Keita [5], Badiane [4] in Dakar reports a duration of 33 days and linked this consultation delay the fact that he did not really see his patients until they realized that the healer could do nothing for them as in our study. This delay in consultation could be due to the widespread belief in the population that it is not advisable to go to a dental surgeon during pregnancy [5]. This idea would be linked in some prenatal care providers hence the interest of conducting intense campaigns in our regions. Dental caries present in all our patients, was the main cause of cellulitis in pregnant women by changing the oral bacterial flora and oral acidification, and the increase in snacking, which synergistically increases the occurrence of caries during pregnancy [1] [2] [8]. The same result was observed by Keita [5], Aboulouidad [1] Nzolo [6]. Pregnancy itself is one of the main contributing factors and aggravates cervicofacial cellulitis. This is explained by the hormonal changes it leads mainly by progesterone which would in turn promote gingival inflammation situation that leads the pregnant woman to the maintenance of a defective oral hygiene. Pregnancy also leads to a decrease in immunity and a change in the oral bacterial flora with predominance of some gram-negative germs, a change in oral $\mathrm{pH}$ increases the frequency of dental caries and cellulitis [2] [5]. Chronic anemia and low economic power are good conditions to develop this infection as late health facility access for all rural patients in this study. Cervico-facial cellulitis is indicative of severity, with fever and trismus (61.90\%). of our patients, (85.71\%) for Keita [5], 100\% trismus Aboulouidad [1]. In this study, odynophagia was (23.81\%), Benzarti found a proportion of $6.6 \%$ [9]. 1/3 of patients with dyspnoea, Njifou note 19\% [10]. This dyspnea is due to obstruction of the respiratory tract by laryngeal edema, basal-lingual pharyngeal obstruction or Inflammation of the respiratory tract by the emptying of a purulent collection [6]. In our survey, diffuse cervicofacial cellulitis was predominant with 14 cases (66.67\%). Authors [1] [6] report in the order, $88.88 \%$ and $100 \%$ of diffuse cervicofacial cellulitis. The physiological changes observed during pregnancy expose women to serious infections and complications [1] [7] [9]. This would explain the diffuse advanced stage of our patients in accordance with the literature [1] [4] [12]. 
The frequency of suppurated forms could be related to the long delay before specialist consultation, the defective oral hygiene and also due by first resort to traditional practitioners. Drug treatment is mainly based on combination of antibiotics and analgesics, with short administration (3-day) of anti-inflammatory steroids. This therapeutic attitude was adopted also by Aboulouidad [1]. Surgical act was based on incision-drainage of the purulent collection, avulsion of decayed teeth in the cause of the affection. This treatment was performed under locoregional anesthesia in all of our patients as used almost by many authors [4] [5]. The mean duration of hospitalization was 21.66 days with extrems 4 and 42 days, extrems 16 and 45 days mean 31 days for Benzarti [9]. Our patients were cured (76.19\%) Nevertheless the prognosis (Table 2) remained bad because of the long delay (more than 30 days) before the specialized, consultation 1/5 cases died. Fetal prognosis was also poor 2 abortions, 7 premature deliveries and 9 stillbirths before hospitalization (52.38\%). For Aboulouida, a single case of premature birth, a healthy newborn (33.33\%) [1]. For Nzolo, 2 cases of abortions, a stillbirth and a threat of premature labor.

\section{Conclusion}

Cervico-facial cellulitis is a serious condition during pregnancy. The prognosis is good by an effective and early treatment; nevertheless, in long delay before care, maternal and fetal morbidity/mortality could be important. The treatment was medicinal and surgical. To avoid it, health care providers (nursing, midwives and obstetricians) must sensibilised particularly pregnant women on the importance of good oral hygiene. Odonto-stomatological consultation must be systematic to least oral affection.

\section{Conflicts of Interest}

The authors declare no conflicts of interest regarding the publication of this paper.

\section{References}

[1] Aboulouidad, S.l., Kharbouch, J.A., et al. (2017) Cellulite cervico-faciale chez la femme enceinte au service de ChirMaxillofac du CHU de Marrakech.

[2] Julie, J. (2009) Santé bucco-dentaire grossesse et prévention. Mémoire sage-femme. Université Henri Poincaré, Nancy, 61.

[3] David, B. (2005) Les 3cellulites d'origine dentaire classification étiologique, bactériologique et traitement. Illustrations cliniques. Thèse de Chir. dentaire. Université Henry Poincaré Nancy, 43-67.

[4] Badiane, C. (2001) Aspects clinique et thérapeutique des cellulites cervico-faciales d'origine dentaire étude prospective de 55 cas réalisée dans les services de stomatologie et d'ORL du CHU le DANTEC (Dakar). Thèse. Chir dentaire, Dakar, 40-46.

[5] Keita, D., Timbo, S.K., Keita, M., et al. (2014) Cellulite cervico-faciale au cours de la grossesse à propos d'une série de 10 cas au Mali au CHU Gabriel Toure de Bamako. Bulletin de la Société de pathologie exotique, 107, 312-316. https://doi.org/10.1007/s13149-014-0401-6 
[6] Nzolo, B.D., Dilu, N.J., Bolenge, I.J., et al. (2009) Grossesse et cellulite d'origine dentaire (à propos de 9 cas) et revue de littérature aux cliniques universitaires de Kinshasa. Annals of African Medicine, 3, 371-375.

[7] Adja, B.S. (2007) Aspects cliniques et thérapeutiques des cellulites peri maxillaires dans le département de MBACKE. Thèse Chir Dent. Université Cheick Anta Diop de Dakar, 71-92.

[8] Sami, R., Laila, O., Rhizlane, E.K., et al. (2013) Les cellulites cervico-faciales (à propos de 130 cas) au service d'ORL et de Chir. Maxillo-fac de Casablanca, Maroc de l'hôpital 20 Aout. Pan African Médical Journal, 2.

[9] Benzarti, S.A. Mardassi, R.B.M., et al. (2007) Les cellulites cervico-faciales d'origine dentaire (à propos de 150 cas). Journal STORL, No. 9, 24-28.

[10] Njifou, N., Essama, L., Kouotou, A.E., et al. (2014) Cellulites cervico-faciales en milieu Hospitalier de Cameroun. Health Sciences and Diseases, 15, 1-3.

[11] Boukerche, A. (2016) Cellulites cervico-faciales au CHU d'Oran. 6e congrès national d'ORL (Saonorl et CCF). 8-15.

[12] Faustine, L. (2007) Petites pathologies de la grossesse et solutions micro-nutritionnelles. Thèse. Pharmacologie. Université de Nantes, 5-19. 